Gut, 1971, 12, 654-660

\title{
Polyethylene glycol 4000 as a continuously administered non-absorbable faecal marker for metabolic balance studies in human subjects
}

\author{
R. WILKINSON
}

From the Medical Research Council Mineral Metabolism Unit, The General Infirmary, Leeds

SUMMARY The use of polyethylene glycol 4000 as a non-absorbable, continuously fed faecal marker is described. The intestinal handling and transit of polyethylene glycol is compared with that of chromium sesquioxide and barium sulphate. Polyethylene glycol is an acceptable non-absorbable faecal marker for calcium, phosphorus, and fatty acids, and has several features which commend its use in preference to insoluble chromium sesquioxide and barium sulphate particularly when marking water-soluble dietary constituents.

Kreula (1947) was the first to carry out continuous faecal marking of metabolic balance investigations with chromium sesquioxide $\left(\mathrm{Cr}_{2} \mathrm{O}_{3}\right)$ and he has been followed by many workers including Whitby and Lang (1960) and Rose (1964). Barium sulphate $\left(\mathrm{BaSO}_{4}\right)$ has been used as a non-absorbable marker (Dick, 1967; Figueroa, Jordan, and Bassett, 1968) and more recently Dick (1969) has used cuprous thiocyanate. All these authors have shown an increase in the reproducibility of balance data due to a more accurate assessment of the faecal component using a continuously fed non-absorbable marker.

Polyethylene glycol 4000 (PEG) has been employed as a non-absorbable faecal marker in animal studies (Hyden, 1956; Corbett, Greenhalgh, Gwynn, and Walker, 1958; Manners and Kidder, 1968). Only one report of its use in man for this purpose can be found in the literature but no attempt was made to validate the use of PEG, since total faecal recoveries were not reported (Beeken, 1967).

The present paper reports the results of using PEG as a continuously fed non-absorbable faecal marker for calcium and phosphorus balances. A comparison of PEG with $\mathrm{Cr}_{2} \mathrm{O}_{3}$ and $\mathrm{BaSO}_{4}$ is presented. The use of PEG to correct faecal fatty acid output is also described.

\section{Procedure}

All the patients were in a metabolic ward and the general principles of Reifenstein, Albright, and Wells (1945) were observed. Diets were prepared under the supervision of a dietitian and any given Received for publication 27 May 1971. patient ate the same normal diet every day throughout the study.

The study was designed to give an equilibration period of five or six days on diet and markers followed by two consecutive seven-day periods of balance. The patients defaecated directly into stainless steel containers held in a suitable commode. The faeces passed in the equilibration period were pooled and then two seven-day faecal collections of the balance were made. Toilet paper was not collected.

Daily faecal collections were made for the two weeks of balance in one patient taking PEG. In six patients taking PEG a post-balance faecal collection was made. During this period the administration of markers was discontinued and the patients ate a free diet. Faeces were collected until the PEG was completely excreted.

Eleven patients were given both $\mathrm{Cr}_{2} \mathrm{O}_{3}$ and PEG throughout their study and another 11 patients were given both $\mathrm{Cr}_{2} \mathrm{O}_{3}$ and $\mathrm{BaSO}_{4}$. One additional patient took all three markers simultaneously.

In the second part of the study the recoveries of PEG in a seven-day period of balance following a seven-day period of equilibration on diet and PEG are reported. There are 165 observations on 64 patients in this part of the study.

In all cases $500 \mathrm{mg}$ of the appropriate markers, in capsules, was administered three times a day with the main meals during the equilibration and balance periods.

Polyethylene glycol 4000 (Hopkin and Williams Ltd, Chadwell Heath, Essex) was powdered and filled into capsules by hand to $500 \mathrm{mg} \pm 5 \mathrm{mg}$. For 
the second part of the study a special batch of PEG capsules was obtained from Sandoz Products Ltd (London). Since PEG is not a definite chemical compound but a mixture of polymers with slightly different molecular weights, the relative proportions varying with the batch manufactured, the standards were made from the same batch of PEG that was used to prepare the patients' capsules. Care was taken over the medication of patients on balance because PEG is used in certain oral pharmaceutical formulations.

Barium sulphate BP was also hand-filled into capsules to the same tolerance limits as PEG. Chromium sesquioxide capsules were obtained from Sandoz Products Ltd (London).

\section{Analytical Methods}

Faeces were homogenized in the collection container with three times their weight of deionized distilled water using a Silverson AXR homogenizer. Whilst the homogenizer was still running aliquots of the homogenate (weighed on a Salter top-pan balance $0.01 \mathrm{~g}$ ) were taken for the appropriate analyses.

The digestion and oxidation steps in the estimation of chromium sesquioxide were carried out, with suitable safety precautions, using the method of Daly and Anstall (1964) The resulting dichromate solution was determined colorimetrically according to the method described by Clarkson (1967).

The gravimetric method of Dick (1967) was used to estimate $\mathrm{BaSO}_{4}$. Filtration of the $\mathrm{BaSO}_{4}$, dissolved in alkaline disodium ethylenediamine tetra-acetic acid solution through two sheets of Whatman no. 115 filter paper, removed $\mathrm{Cr}_{2} \mathrm{O}_{3}$ if it was also present in the faeces.

The turbidimetric method of Malawer and Powell (1967) was modified to estimate PEG on $1.00 \mathrm{~g}$ aliquots of faecal homogenate. The use of Whatman no. 542 filter paper for the filtration stage after protein precipitation removed any $\mathrm{Cr}_{2} \mathrm{O}_{3}$ or $\mathrm{BaSO}_{4}$ present in the faeces and produced a clear, colourless filtrate. Since there was no difference between the estimate of PEG standards in faeces and PEG standards in water the latter were used routinely. The removal of the fine $\mathrm{BaSO}_{4}$ precipitate from the standard solutions after the protein precipitation stage often required the use of two filter papers.

Calcium and phosphorus were determined by AutoAnalyzer techniques on ashed aliquots of faecal homogenate taken up in acid. Total faecal fatty acids were estimated according to a modification of the method of van der Kamer, Huinik, and Weyers (1949) as reported by Varley (1962). Analyses of all markers, calcium, inorganic phosphorus, and fatty acids were the mean of duplicate estimations.

\section{Results}

\section{RECOVERIES OF MARKERS FROM FAECES}

The recoveries of $\mathrm{Cr}_{2} \mathrm{O}_{3}, \mathrm{BaSO}_{4}$, and PEG added directly to marker free faeces are shown in Table $I$. None of the markers interfered with the recovery of any of the other two markers and zero recoveries of all three markers were obtained from six faecal samples containing no markers.

\begin{tabular}{llll}
\hline Marker & $\begin{array}{l}\text { Mean } \\
\text { Recovery } \\
(\%)\end{array}$ & $S D(\%)$ & $\begin{array}{l}\text { No. of } \\
\text { Estimations }\end{array}$ \\
\hline Chromium sesquioxide & 98.79 & 0.723 & 10 \\
Barium sulphate & 98.83 & 1.392 & 16 \\
Polyethylene glycol 4000 & 99.60 & 1.612 & 18 \\
\hline
\end{tabular}

Table I Recoveries of markers added directly to faeces

The error of the analytical method, for each of the three markers, is shown in Table II. If $x_{1}$ and $x_{2}$

\begin{tabular}{llll}
\hline Marker & $\begin{array}{l}\text { Error of a } \\
\text { Single } \\
\text { Estimate of } \\
\text { Marker }\end{array}$ & $\begin{array}{l}\text { No. of } \\
\text { Sample } \\
\text { Estimates in } \\
\text { Duplicate }\end{array}$ & $\begin{array}{l}\text { Error of } \\
\text { Marker } \\
\text { Method when } \\
\text { Mean of } \\
\text { Duplicate } \\
\text { Estimations } \\
\text { Used }\end{array}$ \\
\hline $\begin{array}{l}\text { Chromium sesquioxide } \\
\text { Barium sulphate }\end{array}$ & 1.752 & 28 & 1.323 \\
Polyethylene glycol 4000 & 1.177 & 25 & 1.475 \\
1.527 & 25 & 1.236 \\
\hline
\end{tabular}

Table II Error of marker determinations

represent duplicate estimations of the percentage of the administered dose of marker in a given faecal collection then the error of a single estimate of the marker, $\sigma$, is given by

$$
\sigma=\sqrt{\frac{\sum\left(x_{1}-x_{2}\right)^{2}}{2 n}}
$$

where $n$ is the number of collections estimated in duplicate. The error of the marker determination when the mean of duplicate estimations is used is $\sigma / \sqrt{ } 2$.

\section{RECOVERIES OF MARKERS FROM PATIENTS}

Table III shows the total faecal recoveries of all the PEG given throughout the study from the six patients on whom post-balance faecal collections were made. There is a mean faecal recovery of $98.65 \%$ of the administered PEG, the range being $95.5 \%-101.5 \%$. A histogram distribution of the individual seven-day faecal recoveries of PEG in the second part of the study is shown in Figure 1. The recovery of PEG is normally distributed and has a mean of $99.29 \%$ of the administered dose, which is 


\begin{tabular}{lc}
\hline Patient & $\begin{array}{l}\text { Percentage of Total Administered Dose of } \\
\text { PEG Recovered from Faeces }\end{array}$ \\
\hline 1 & 95.5 \\
2 & 101.5 \\
3 & 99.9 \\
4 & 95.06 \\
5 & 100.16 \\
6 & 99.8 \\
Mean & 98.65 \\
SD & 2.68 \\
\hline
\end{tabular}

Table III Total faecal recovery of polyethylene glycol 4000 administered to patients

not significantly different from $100 \%(\mathrm{t}=0 \cdot 386)$. PEG, therefore, is completely recoverable in the faeces and is being estimated accurately.

The relationship of the faecal recoveries of $\mathrm{Cr}_{2} \mathrm{O}_{3}$ and PEG for the 12 patients given these two markers should be evenly distributed around the $45^{\circ}$ line of equality if they are excreted at the same rate. However, in the equilibration period more PEG is excreted than $\mathrm{Cr}_{2} \mathrm{O}_{3}$ the points all lying below the $45^{\circ}$ line (Fig. 2). In week 1 the points still tend to be slightly below the expected line and it is not until week 2 that faecal $\mathrm{Cr}_{2} \mathrm{O}_{3}$ output equals faecal PEG output. Figure 3 shows the corresponding data for $\mathrm{Cr}_{2} \mathrm{O}_{3}$ and $\mathrm{BaSO}_{4}$. Slightly more $\mathrm{BaSO}_{4}$ than $\mathrm{Cr}_{2} \mathrm{O}_{3}$ is excreted in the equilibration period, but probably by week 1 and definitely by week 2 the faecal outputs of $\mathrm{Cr}_{2} \mathrm{O}_{3}$ and $\mathrm{BaSO}_{4}$ are equal.

The interrelationship of faecal output and transit time of the markers is well illustrated by the results from the patient who took all three markers simultaneously (Fig. 4). In the equilibration period more PEG is excreted than $\mathrm{BaSO}_{4}$, and more $\mathrm{BaSO}_{4}$ is excreted than $\mathrm{Cr}_{2} \mathrm{O}_{3}$. In week 2 of the balance the faecal excretions of all the markers are the same, the lines in Fig. 4 being almost parallel. Five days after discontinuing marker administration all the PEG is completely recovered. However, two days after this $\mathrm{BaSO}_{4}$ and $\mathrm{Cr}_{2} \mathrm{O}_{3}$ are still being excreted in the faeces and have not yet been completely recovered.

PEG CORRECTION OF FAECAL CALCIUM, PHOSPHORUS, AND FATTY ACID OUTPUTS

Figure 5 shows the daily faecal calcium and phosphorus outputs of the one patient on whom daily faecal collections were made throughout the two weeks of balance. Knowing the PEG content of each sample, PEG-corrected 24-hour faecal calcium and phosphorus values were calculated. In contrast to the uncorrected values the PEG-corrected daily faecal calcium and phosphorus values are virtually constant. Similarly the daily faecal fatty acid outputs of a patient on eight consecutive days of balance are

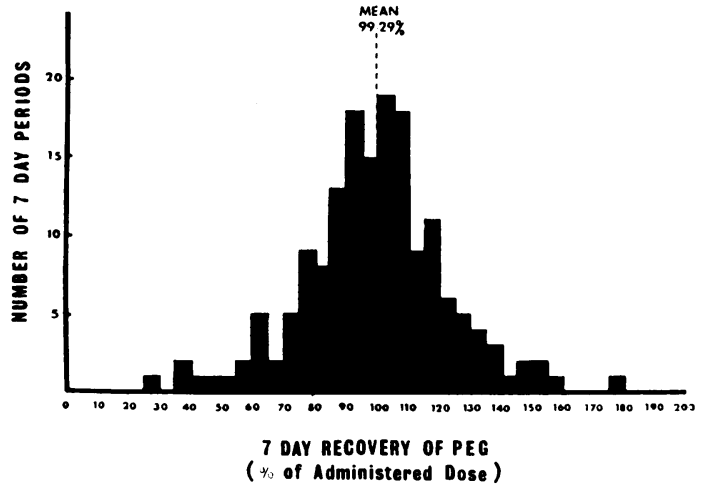

Fig. 1. Histogram showing distribution of seven-day faecal recoveries of PEG expressed as a percentage of the dose administered in seven days. The patients were equilibrated before the faecal collection was begun. Mean recovery of $P E G=99.29 \%(S D=23.57 \%$, $S E M=1.84 \%$ ).
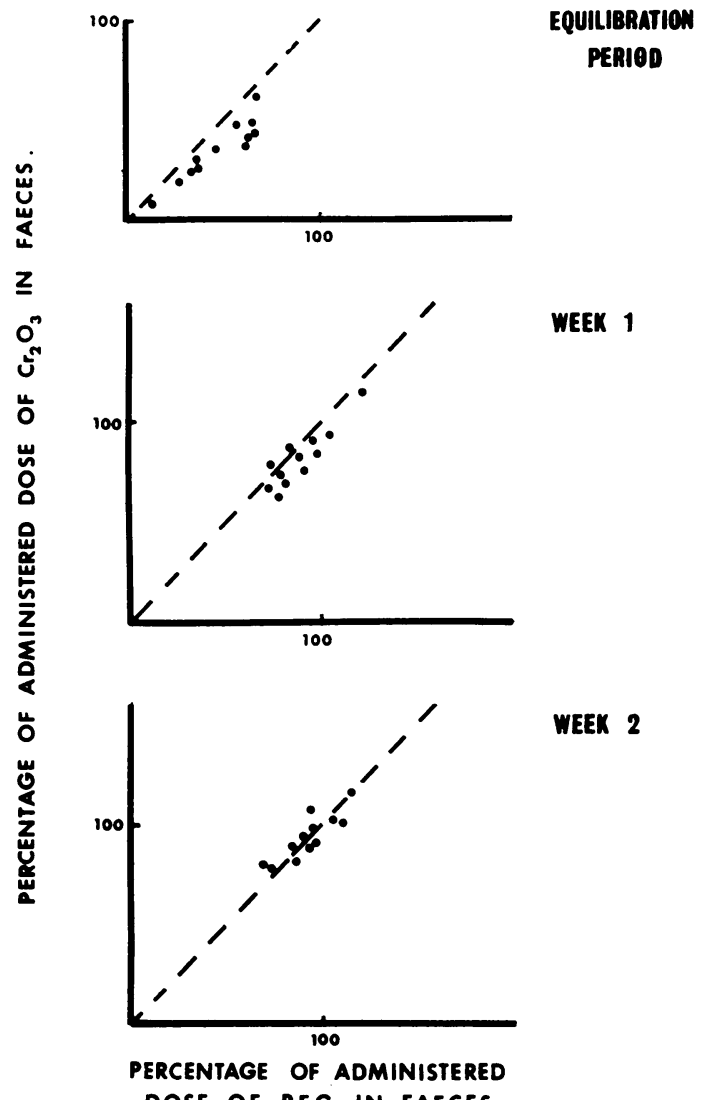

WEEK 1

WEEK 2

Fig. 2. Comparison of the faecal recoveries of $\mathrm{Cr}_{2} \mathrm{O}_{3}$ and PEG in the equilibration period and weeks 1 and 2 of balance. (The dotted line is the $45^{\circ}$ line of equality.) 


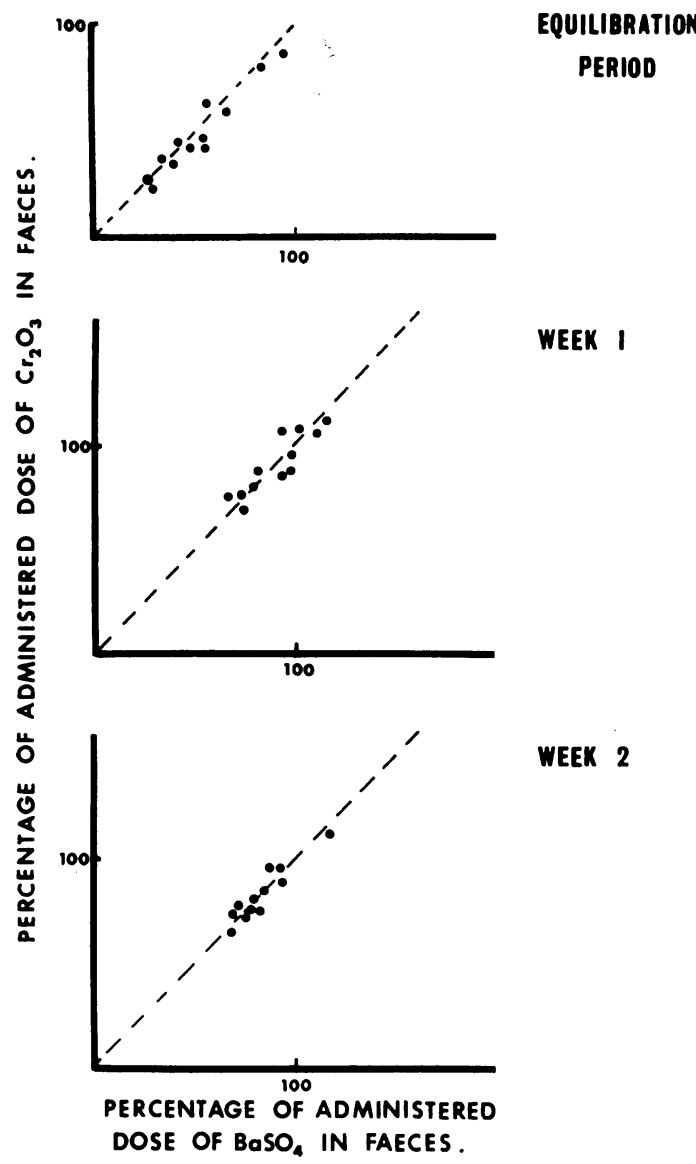

Fig. 3. Comparison of the faecal recoveries of $\mathrm{Cr}_{2} \mathrm{O}_{3}$ and $\mathrm{BaSO}_{4}$ in the equilibration period and weeks 1 and 2 of balance. (The dotted line is the $45^{\circ}$ line of equality.) shown in Figure 6. There is much less variation in the PEG corrected than in the uncorrected faecal fatty acid values.

\section{Discussion}

All three markers were well tolerated by the patients and no toxic effects were observed. None of the 76 patients taking PEG showed any side effects attributable to the administration of this marker.

The mean recovery of $99.60 \%$ of PEG added directly to faeces is comparable to that of $\mathrm{Cr}_{2} \mathrm{O}_{3}$ and $\mathrm{BaSO}_{4}$ (Table I). The errors of all the methods of analysis (Table II) are acceptable and similar to those published (Whitby and Lang, 1960).

The turbidimetric estimation of PEG is accomplished easily and accurately with commonly available equipment and there is no danger of an explosion in the estimation of PEG as there is in the analysis of $\mathrm{Cr}_{2} \mathrm{O}_{3}$ (Analytical Methods Committee, 1959). The PEG method is less laborious and exacting than the gravimetric determination of $\mathrm{BaSO}_{4}$, though recently Dick (1968) has reported an emission flame photometric method which reduces the time taken for $\mathrm{BaSO}_{4}$ estimations.

Schaffer and Critchfield (1947) concluded that PEG was not absorbed from the gastrointestinal tract of rat or man and PEG is the most popular inert marker used for intubation studies (Soergel, 1968). Mean faecal recoveries of between $96.7 \%$ and $99.0 \%$ have been reported after the ingestion of large single doses of PEG by human subjects (Hyden, 1956; Borgström, Dahlqvist, Lundh, and Sjovall, 1957; Soergel and Hogan, 1967; Shields, Harris, and Davies, 1968).

The mean total faecal recovery of $98.65 \%$ of the

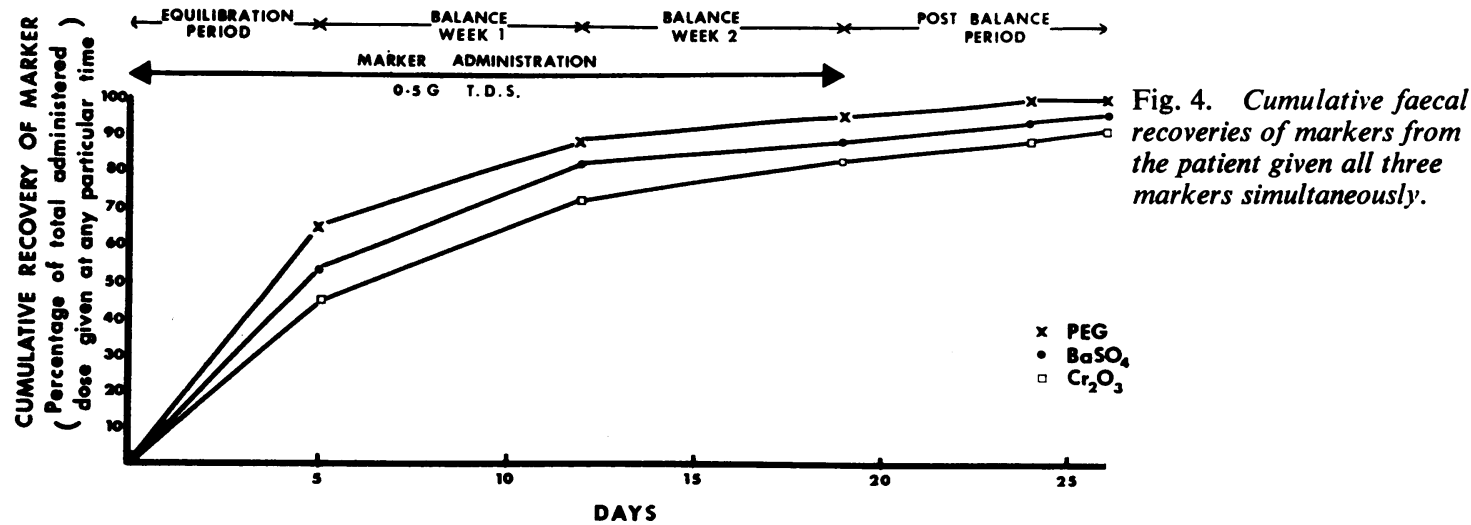



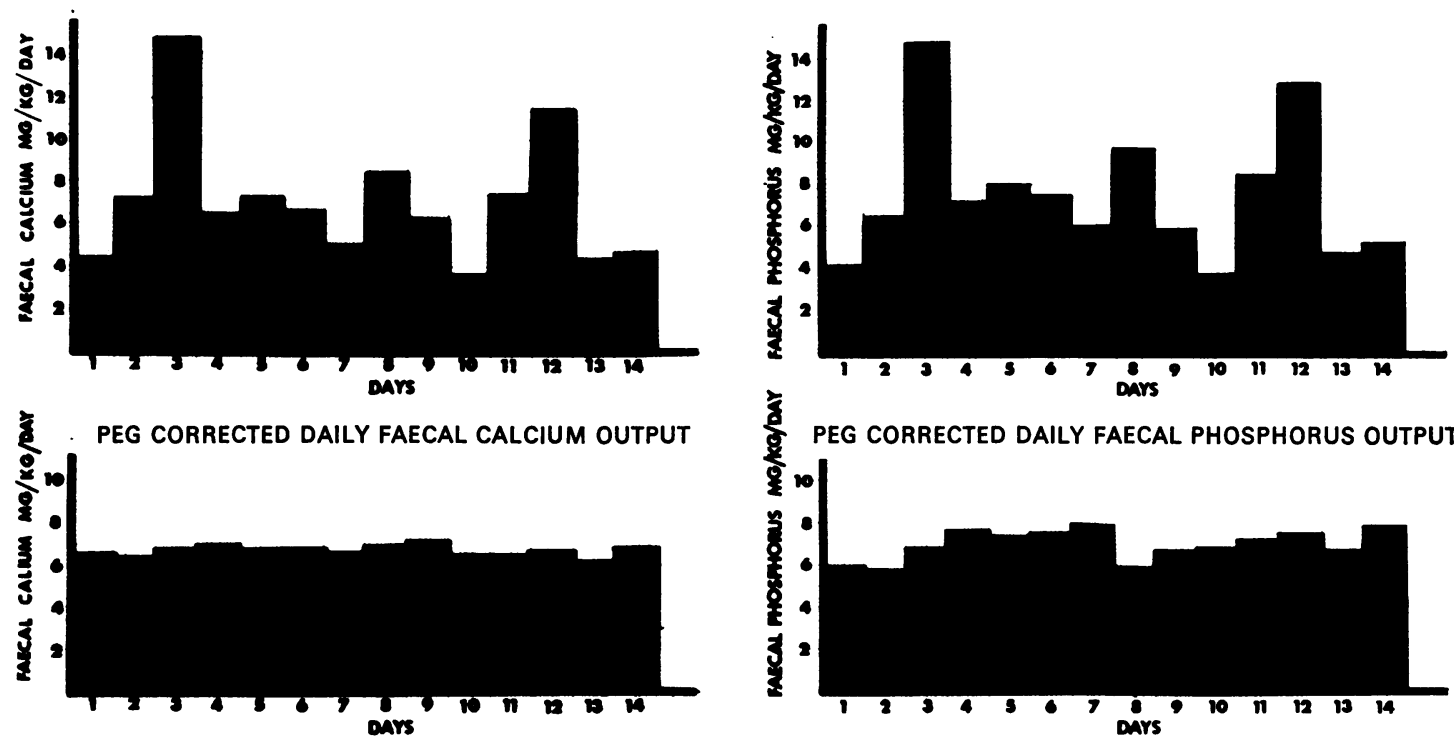

a

b

Fig. 5. Daily faecal calcium and phosphorus excretion for 14 days of balance with and without PEG correction.

UNCORRECTED FAECAL FATTY ACIDS

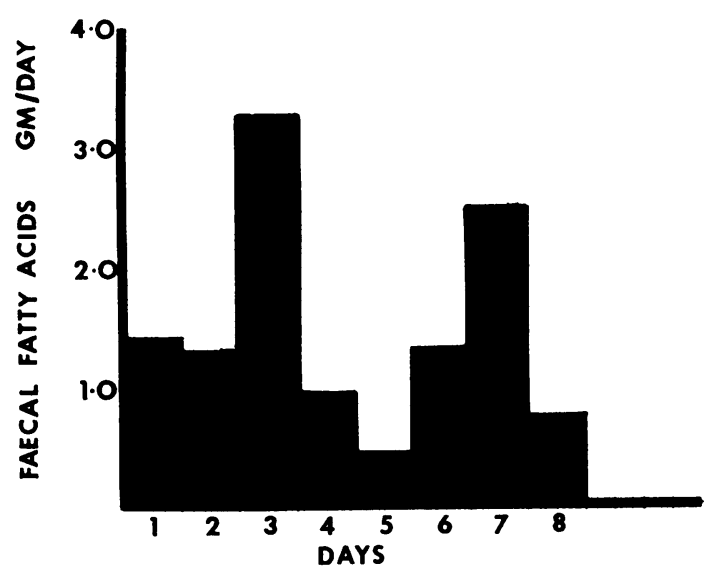

a
PEG CORRECTED FAECAL FATTY ACIDS

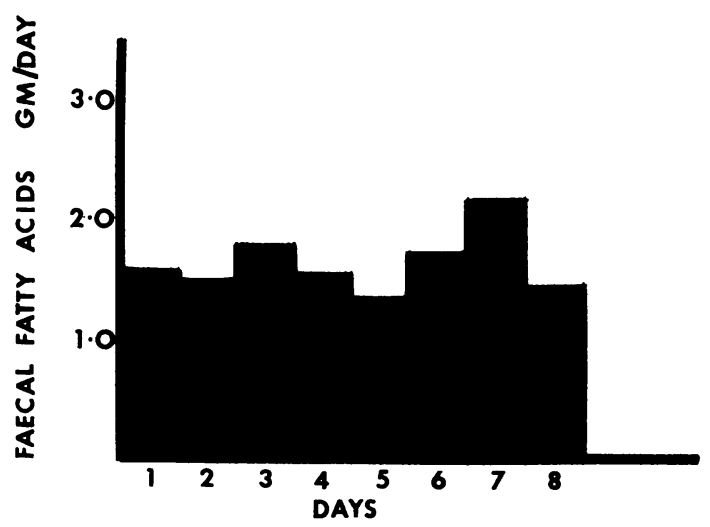

b

Fig. 6. Daily faecal fat excretion for eight consecutive days of balance with and without PEG correction. 
administered PEG (Table III) is comparable to the total recovery of $93 \%$ of the administered $\mathrm{Cr}_{2} \mathrm{O}_{3}$ by Rose (1964) and $97 \%$ of the administered $\mathrm{BaSO}_{4}$ by Dick (1967). In the second part of the study the normal distribution of PEG recovery has a mean of $99 \cdot 29 \%$ of the administered dose (Fig. 1). These results substantiate the previous observations that PEG is not absorbed from the human gastrointestinal tract.

In view of the above findings it is perhaps surprising that Beeken (1967) reported steady-state recoveries of PEG of only $70 \%$. Beeken suggests as one of the possible reasons for this low recovery that his subjects may have failed to take the PEG. Also some of the equilibration periods in the study were as short as three days.

It is apparent from Figs. 2, 3, and 4 that PEG has a more rapid intestinal transit time than $\mathrm{BaSO}_{4}$ which in turn has a slightly faster transit time than $\mathrm{Cr}_{2} \mathrm{O}_{3}$. These differences are most easily observed in the equilibration and post-balance collection periods. However, in week 2 of the balance the excretions of PEG, $\mathrm{Cr}_{2} \mathrm{O}_{3}$, and $\mathrm{BaSO}_{4}$ are the same. The results could be explained if there is a larger dead space in the intestinal tract for $\mathrm{Cr}_{2} \mathrm{O}_{3}$ and $\mathrm{BaSO}_{4}$ than for PEG that must be filled before steady-state excretion is attained.

The difference between dead spaces may be due to the fact that PEG is water soluble whereas $\mathrm{BaSO}_{4}$ and $\mathrm{Cr}_{2} \mathrm{O}_{3}$ are insoluble and considerably more dense than food (the density of $\mathrm{Cr}_{2} \mathrm{O}_{3}$ was 5.21 and of $\mathrm{BaSO}_{4} 4 \cdot 50$ ). PEG will move with the water-soluble phase of food and this has an advantage in marking calcium and phosphorus since both are water soluble. However, PEG may be labelling a water-soluble component of the dead space which is smaller than the true dead space for food in the intestine. Alternatively the dead space for $\mathrm{Cr}_{2} \mathrm{O}_{3}$ and $\mathrm{BaSO}_{4}$ may be greater than the true dead space for food. The very fine, dense, insoluble powders of $\mathrm{Cr}_{2} \mathrm{O}_{3}$ and $\mathrm{BaSO}_{4}$ tend to adhere to any surface on which they are spread. The large surface area and many small villous folds of the intestinal tract may trap the insoluble markers producing a larger dead space for $\mathrm{Cr}_{2} \mathrm{O}_{3}$ and $\mathrm{BaSO}_{4}$ than for either food or watersoluble PEG.

Davignon, Simmonds, and Ahrens (1968) have shown that $20 \%$ of their patients on prolonged balance studies failed to attain ideal steady-state excretion of $\mathrm{Cr}_{2} \mathrm{O}_{3}$. They demonstrated that some of these patients had sequestration and accumulation of $\mathrm{Cr}_{2} \mathrm{O}_{3}$ in the large bowel, supporting the hypothesis that $\mathrm{Cr}_{2} \mathrm{O}_{3}$ is not always handled in the same way as food residues by the intestine.

Fifteen of 52 balances reported by Whitby and Lang (1960) were not acceptable because the patients had not reached steady state excretion with respect to $\mathrm{Cr}_{2} \mathrm{O}_{3}$. Whitby and Lang also warned of the possibility of streaming of the intestinal contents occurring and under these conditions the density of $\mathrm{Cr}_{2} \mathrm{O}_{3}$ might cause it to sediment and be carried irregularly along the intestinal lumen. Sequestration is less liable to occur with PEG than with insoluble $\mathrm{Cr}_{2} \mathrm{O}_{3}$ or $\mathrm{BaSO}_{4}$ and streaming would not cause water-soluble PEG to sediment.

The wide variations of consecutive daily faecal calcium and phosphorus outputs are virtually eliminated when corrected by their respective PEG content (Fig. 5). Since the calcium to PEG and the phosphorus to PEG ratio in these faecal samples is constant then PEG is evenly distributed in the faeces with respect to calcium and phosphorus.

Wiggins and Dawson (1961) showed that PEG being water soluble emptied more quickly from the stomach in the water-soluble phase than did the fat of a test meal. Vavřinková and Krondl (1965) reported that PEG, at concentrations of $1 \mathrm{mg} / \mathrm{ml}$ or greater, inhibited lipase from hog pancreas and human duodenal juice in vitro and therefore PEG may not be suitable for the investigation of fat absorption. No increase in the faecal fatty acid excretion of patients taking PEG has been observed and after a suitable equilibration period PEG can be used to correct daily faecal fatty acid output with some success (Fig. 6). Thus PEG, although water soluble, is relatively evenly distributed in the faeces with respect to fatty acids.

To reduce any possible effect on lipase activity in vivo the dose of PEG can be decreased to $250 \mathrm{mg}$ three times a day. The lower concentration of PEG can be estimated by reading the turbidity at $420 \mathrm{~m} \mu$ as suggested by Boulter and McMichael (1970).

The criteria for the ideal non-absorbable marker stated by Whitby and Lang (1960) and Fordtran (1966) are fulfilled equally well by PEG as by the established markers $\mathrm{Cr}_{2} \mathrm{O}_{3}$ and $\mathrm{BaSO}_{4}$. In fact PEG has features which commend its use in certain circumstances. In contrast to the estimation of $\mathrm{Cr}_{2} \mathrm{O}_{3}$ the estimation of PEG is not hazardous. Because of its smaller intestinal dead space equilibration is achieved more quickly with PEG than with the two insoluble markers and this allows a more rapid assessment of the balance. Being water soluble PEG more closely resembles calcium, inorganic phosphate, and other ions than do insoluble $\mathrm{Cr}_{2} \mathrm{O}_{3}$ and $\mathrm{BaSO}_{4}$.

The large spread of the seven-day faecal PEG outputs in Fig. 1 again emphasizes the absolute necessity for continuous faecal marking in metabolic balance investigations. The $95 \%$ limits for a sevenday timed faecal collection vary from the equivalent of 3.7 days to 10.3 days excretion of food residue. PEG is recommended as a non-absorbable con- 
tinuously fed faecal marker particularly for dietary constituents which are water soluble.

The author wishes to acknowledge the interest and advice of Professor B. E. C. Nordin and to thank him for permission to publish details of studies on patients under his care.

My thanks go to Dr Munro Peacock and Dr Joan Zanelli for advice in the preparation of the manuscript, to L. Bulusu for advice on statistical aspects of the work, to the nursing and dietetic staff of the metabolic units at Leeds General Infirmary, to the staff of the pharmacy for the hand preparation of the PEG and $\mathrm{BaSO}_{4}$ capsules used in the initial stages of the work, and to Miss S. Barker, Miss W. Oldfield, M. Youssaf Khan, and T. Thompson for valuable technical assistance during parts of this work. I am also indebted to Sandoz Products Ltd (London), for preparing the capsules of PEG used in the second part of the study.

\section{References}

Analytical Methods Committee (1959). Notes on perchloric acid and its handling in analytical work. Analyst, 84, 214-216.

Beeken, W. L. (1967). Clearance of circulating radiochromated albumin and erythrocytes by the gastrointestinal tract of normal subjects. Gastroenterology, 52, 35-41.

Borgström, B., Dahlqvist, A., Lundh, G., and Sjovall, J. (1957). Studies of intestinal digestion and absorption in the human. J. clin. Invest., 36, 1521-1536.

Boulter, J. M., and McMichael, H. B. (1970). Modification of polyethylene glycol estimation suitable for use with small mammals. Gut, 11, 268-270.

Clarkson, E. M. (1967). A rapid method for the determination of chromium sesquioxide in faecal homogenates. Clin. chim. Acta, 16, 186-188.

Corbett, J. L., Greenhaigh, J. F. D., Gwynn, P. E., and Walker, D. (1958). Excretion of chromium sesquioxide and polyethyleneglycol by dairy cows. Brit. J. Nutr., 12, 266-276.

Daly, J. R., and Anstall, H. B. (1964). The determination of chromium sesquioxide in faeces by flame spectrophotometry. Clin. chim. Acta, 9, 576-580.
Davignon, J., Simmonds, W. J., and Ahrens, E. H., Jr. (1968). Usefulness of chromic oxide as an internal standard for balance studies in formula-fed patients and for assessment of colonic function. J. clin. Invest., 47, 127-138.

Dick, M. (1967). Use of barium sulphate as a continuous marker for faeces. J. clin. Path., 20, 216-218.

Dick, M. (1968). Estimation of barium sulphate in faeces by emission flame photometry. J. clin. Path., 22, 378.

Dick, M. (1969). Use of cuprous thiocyanate as a short-term continuous marker for faeces. Gut, 10, 408-412.

Figueroa, W. G., Jordan, T., and Bassett, S. H. (1968). Use of barium sulfate as an unabsorbable fecal marker. Amer. J. clin. Nutr., 21, 1239-1245.

Fordtran, J. S. (1966). Marker perfusion techniques for measuring intestinal absorption in man. Gastroenterology, 51, 1089-1093.

Hyden, S. (1956). The recovery of polyethylene glycol after passage through the digestive tract. K. LantbrHögsk. Annln., 22, 411-422.

Kreula, M. S. (1947). Absorption of carotene from carrots in man and the use of the quantitative chromic oxide indicator method in the absorption experiments. Biochem. J., 41, 269-273.

Malawer, S. J., and Powell, D. W. (1967). An improved turbidimetric analysis of polyethylene glycol utilizing an emulsifier. Gastroenterology, 53, 250-256.

Manners, M. J., and Kidder, D. E. (1968). Polyethylene glycol as a marker in piglet diets with a high dry-matter content. Brit. $J$. Nutr., 22, 515-526.

Reifenstein, E. C., Jr., Albright, F., and Wells, S. L. (1945). The accumulation, interpretation and presentation of data pertaining to metabolic balances, notably those of calcium, phosphorus and nitrogen. J. clin. Endocr., 5, 367-395.

Rose, G. A. (1964). Experiences with the use of interrupted carmine red and continuous chromium sesquioxide marking of human faeces with reference to calcium, phosphorus and magnesium. Gut, 5, 274-279.

Schaffer, C. B., and Critchfield, F. H. (1947). The absorption and excretion of the solid polyethylene glycols. J. Amer. pharm. Ass. sci. Ed., 36, 152-157.

Shields, R., Harris, J., and Davies, M. W. (1968). Suit ability of polyethylene glycol as a dilution indicator in the human colon. Gastroenterology, 52, 331-333.

Soergel, K. H. (1968). Inert markers. Gastroenterology, 54, 449-452.

Soergel, K. H., and Hogan, W. J. (1967). On the suitability of poorly absorbed markers as dilution indicators in the gastrointestinal tract. Gastroenterology, 54, 1056-1057.

Varley, H. (1962). Practical Clinical Biochemistry, 3rd Ed., p. 353. Heinemann, London.

Vavłinková, H., and Krondl, A. (1965). Use of polyethylene glycol in investigation of absorption of fat. Nature, 206, 293-294.

Whitby, L. G., and Lang, D. (1960). Experience with the chromic oxide method of fecal marking in metabolic balance investigations on humans. J. clin. Invest., 39, 854-863.

Wiggins, H. S., and Dawson, A. M. (1961). An evaluation of unabsorbable markers in the study of fat absorption. Gut, 2, 373-376. 